\title{
PEMBUATAN GLISEROL TRIBENZOAT DENGAN PROSES ESTERIFIKASI MENGGUNAKAN KATALIS H-ZEOLIT TERAKTIVASI OLEH ASAM KLORIDA DAN ASAM SULFAT
}

\author{
Mutiara Valentina M*, Ekelesia Martina, Zuhrina Masyithah \\ Departemen Teknik Kimia, Fakultas Teknik, Universitas Sumatera Utara, \\ Jl. Almamater Kampus USU Medan 20115, Indonesia \\ *Email: mutiara_nsn@yahoo.com
}

\begin{abstract}
Abstrak
Esterifikasi merupakan salah satu metode yang sering digunakan dalam mengkonversi gliserol. Gliserol tribenzoat merupakan produk turunan gliserol yang biasa digunakan sebagai bahan plasticizer untuk industri polimer, bahan tambahan pada makanan, bahan anti air pada tinta printer, dan masih banyak lagi. Penelitian ini bertujuan untuk melakukan kajian pembuatan gliserol tribenzoat dengan proses esterifikasi dengan menggunakan katalis zeolit alam yang diaktivasi dengan asam klorida dan asam sulfat, sehingga diperoleh $\%$ berat (w/w gliserol) zeolit optimum, serta potensi zeolit untuk digunakan kembali (recycle). Zeolit alam diaktivasi dengan asam $4 \mathrm{M}$ selama 6 jam, lalu dikalsinasi didalam furnace $500{ }^{\circ} \mathrm{C}$ selama 5 jam. Selanjutnya dalam proses esterifikasi gliserol $90 \%$ direaksikan dengan dengan asam benzoat yang dilarutkan dalam metanol, dengan perbandingan mol asam benzoat dengan gliserol yaitu 3,5:1, suhu reaksi $65{ }^{\circ} \mathrm{C}$, dengan kecepatan pengaduk $200 \mathrm{rpm}$, variasi $\%$ berat katalis (w/w gliserol) yaitu 5\%, 6\%,7\%, dan 8\%, serta dilakukan recycle katalis sebanyak 3 kali. Hasil karakterisasi FTIR menghasilkan penyesuaian tetap yang menunjukkan bahwa produk yang dihasilkan adalah gliserol tribenzoat. $\mathrm{H}$-zeolit yang diaktivasi dengan $\mathrm{HCl}$ menghasilkan rendemen tertinggi pada persen katalis $6 \%$ yaitu 68,992 \%, sedangkan dengan $\mathrm{H}_{2} \mathrm{SO}_{4}$ menghasilkan rendemen tertinggi pada persen katalis $8 \%$ yaitu $69,678 \%$ Katalis H-zeolit yang direcycle masih layak pakai hingga 3 kali recycle dengan persen penurunan rendemen tiap kali recycle $\leq 8 \%$
\end{abstract}

Kata kunci : asam benzoat, esterifikasi, gliserol, gliserol tribenzoat, zeolit

\begin{abstract}
Abstrack
Esterification is one method that is often used in converting glycerol. Glycerol tribenzoate is a derivative product of glycerol which used as a plasticizer for polymer industry, food additives, water repellent material on printer ink, and many more. This research aims to study the making of glycerol tribenzoate through esterification process by using natural zeolit catalyst which is activated with hydrochloric acid, in order to obtain the optimum catalyst \% weight (w/w glycerol), and also to see the potential of recycling the zeolit. Zeolit is activated by $4 M$ for 6 hours, and then calcined in the furnace at $500{ }^{\circ} \mathrm{C}$ for 5 hours. Then continued to esterification process, glycerol $90 \%$ reacted with benzoic acid which dissolved in metanol, with mole ratio of benzoic acid and glycerol at 3,5:1, reaction temperature at $65{ }^{\circ} \mathrm{C}$, and the stirrer speed of $200 \mathrm{rpm}$, the catalyst \% weight is varied at $5 \%, 6 \%, 7 \%$, and $8 \%$, and catalyst recycling is performed 3 times. FTIR characterization result a close match, shows that the product is glycerol tribenzoate. The highest yield of zeolite which activated by $\mathrm{HCl}$ is obtained at $6 \%$ catalyst \% weight i.e 68,992\%, while zeolite that activated by $\mathrm{H}_{2} \mathrm{SO}_{4}$ is obtained at $8 \%$ catalyst \% weight i.e 69,678\%, $\mathrm{H}$-zeolit catalyst is still feasible to use up to 3 times recycling, with percent of yield reduction for each recycle is $\leq 8 \%$.
\end{abstract}

Keywords :benzoic acid, esterification, glycerol, glycerol tribenzoate, zeolit

\section{Pendahuluan}

Tingginya permintaan terhadap bahan bakar yang terbarukan dan rendah polusi telah membuat biodiesel menjadi pilihan yang sangat menarik bagi beberapa negara di dunia. Hal ini menyebabkan peningkatan produksi gliserol, karena gliserol merupakan produk samping yang terbentuk dengan proporsi berat $1: 10$ selama produksi biodiesel [4]. Tingginya jumlah produksi gliserol sebagai produk samping, mengakibatkan penurunan harga pasar gliserol yang kemudian telah membangkitkan minat untuk mengembangkan lebih jauh lagi aplikasi gliserol. Penggunaan gliserol sebagai bahan baku 
mendapat perhatian khusus dalam pengembangan proses sintetis turunan gliserol yang baru dan ramah lingkungan serta berkelanjutan [10].

Salah satu metode yang banyak digunakan untuk memproduksi produk turunan gliserol adalah melalui esterifikasi gliserol. Produk dari konversi gliserol ini bersifat ramah lingkungan dan terbarukan karena bukan merupakan turunan dari minyak bumi [2]. Salah satu turunan gliserol yang banyak dikembangkan adalah gliserol tribenzoat. Produk gliserol tribenzoat ini digunakan untuk aplikasi bahan plasticizer untuk industri polimer, bahan tambahan pada makanan, bahan anti air pada tinta printer, bahan pada pewarna kuku, dan sebagai tambahan pada minyak citrus untuk menaikkan nilai specific gravity minyak $[12,16,19]$.

Berdasarkan penelitian sebelumnya, pembuatan gliserol tribenzoat dilakukan melalui proses esterifikasi, yang menggunakan katalis asam homogen dan enzim. Pada penelitian ini akan digunakan katalis heterogen yang diaktivasi dengan menggunakan asam klorida sehingga membentuk H- zeolit. Proses aktivasi ini dilakukan untuk membersihkan pori, membuang senyawa pengotor, modifikasi luas permukaan serta keasaman [25].

Dengan dilakukannya penelitian ini diperoleh informasi mengenai pengaruh penggunaan katalis $\mathrm{H}$ - Zeolit yang diaktivasi dengan $\mathrm{HCl}$ dalam meningkatkan yield dari gliserol tribenzoat melalui reaksi esterifikasi gliserol dengan asam benzoat, karena sejauh ini belum ada penelitian mengenai pembuatan gliserol tribenzoat dengan menggunakan katalis heterogen, serta melihat kemampuan katalis tersebut untuk digunakan kembali (recycle).

\section{Teori}

Ester adalah kelas penting dalam bahan kimia, memiliki aplikasi diberbagai bidang seperti sebagai pelarut, plasticizer, bidang farmasi, dan barang setengah jadi [9]. Telah dilakukan berbagai penelitian mengenai proses esterifikasi gliserol Rose et al , melakukan eksperimen untuk mensisntesis DAG (Diasilgliserol) melalui esterifikasi asam lemak bebas dan gliserol pada suatu system bebas pelarut menggunakan Lipozyme IM yang disertai dengan pembuangan air secara simultan, menghasilkan yield $85 \%$ DAG [9].

Untuk pembuatan gliserol tribenzoate dengan metode esterifikasi telah dilakukan dengan menggunakan enzim tanpa menggunakan pelarut, dan terbukti dapat dilakukan dengan menggunakan $C$. Antartica lipase B sebagai katalis untuk menghasilkan gliserol monobenzoat [10]. Ada juga yang menggunakan pelarut metanol dan katalis asam homogen [27]

Pada penelitian ini digunakan katalis zeolit alam yang diaktivasi dengan asam klorida dan asam sulfat (H-Zeolit). Kemampuan zeolit sebagai katalis berkaitan dengan tersedianya pusat - pusat aktif dalam saluran antar zeolit. Bila zeolit digunakan pada proses katalitik maka akan terjadi difusi molekul ke dalam ruang kosong antar kristal dan reaksi kimia juga terjadi di permukaan tersebut [3].

Pada reaksi esterifikasi dengan katalis $\mathrm{H}-$ Zeolit terjadi peristiwa perengkahan atau pemutusan ikatan hidrokarbon tidak jenuh dari asam karboksilat oleh katalis H-Zeolit yang mengakibatkan adanya ikatan antara hidrogen pada katalis dengan karbon ikatan rangkap [20].

\section{Metodologi Penelitian}

Bahan yang digunakan dalam penelitian ini adalah gliserol 90\%, asam benzoat, metanol, asam klorida, asam sulfat, dan zeolit alam. Sebelum digunakan zeolit alam akan diaktivasi terlebih dahulu. Zeolit dihaluskan dengan menggunakan ball mill selama 1 jam, kemudian diayak dengan ayakan 100 mesh. Proses pembuatan katalis H-Zeolit dilakukan melalui tahap dealuminasi, pencucian, pengeringan, dan kalsinasi. Proses dealuminasi dilakukan dengan mencampur zeolit alam sebanyak 30 gram dengan asam 4M sebanyak $600 \mathrm{ml}$. Campuran dimasukkan ke dalam labu leher tiga yang dilengkapi dengan magnetic stirer, pendingin balik dan campuran dipanaskan hingga suhu $90^{\circ} \mathrm{C}$ dengan penangas air. Setelah suhu tercapai, waktu pengadukan dihitung selama 6 jam. Zeolit alam kemudian dicuci dengan aquadest hingga semua ion $\mathrm{Cl}^{-}$hilang, lalu zeolit dikeringkan dengan oven. Proses kalsinasi dilakukan dengan memasukkan zeolit hasil dealuminasi ke furnace bersuhu $500^{\circ} \mathrm{C}$ selama 5 jam. Waktu kalsinasi dihitung setelah tercapai suhu $500{ }^{\circ} \mathrm{C}$.

Esterifikasi asam benzoat dengan gliserol dilakukan dengan rasio mol asam benzoat terhadap gliserol 3,5:1, dan katalis H- Zeolit terhadap gliserol adalah 5\%, 6\%,7\%, dan $8 \%$ (w/w gliserol) dengan kecepatan pengadukan $200 \mathrm{rpm}$ dan suhu $65{ }^{\circ} \mathrm{C}$. Asam benzoat dilarutkan dalam $250 \mathrm{ml}$ metanol pada beaker glass. Larutan asam benzoat dan $10 \mathrm{ml}$ gliserol 
$90 \%$ dimasukkan dalam labu leher tiga. Pada labu leher tiga dipasang sebuah termometer, kemudian magnetic stirrer dihidupkan. Hot Plate dihidupkan hingga suhu $65{ }^{\circ} \mathrm{C}$. Setelah suhu 65 ${ }^{\circ} \mathrm{C}$ tercapai, ditambahkan katalis $\mathrm{H}$-zeolit 0,6307 gram kedalam labu leher tiga. Reaksi berlangsung selama 1 jam.

Setelah waktu reaksi 30 menit, H-Zeolit dipisahkan dari larutan produk tribenzoin dengan menggunakan kertas saring kemudian larutan produk tribenzoin dicuci dengan aquadest hingga terbentuk padatan. Padatan yang terbentuk disaring dengan kertas saring, lalu dimasukkan kedalam oven pada suhu $105{ }^{\circ} \mathrm{C}$, hingga berat konstan.

Setelah proses esterifikasi selesai, zeolit tersebut kemudian dicuci kembali menggunakan air dan dipakai ulang dalam proses esterifikasi gliserol lainnya. Air yang digunakan dalam proses pencucian zeolit memiliki $\mathrm{pH}$ netral dan bersuhu $50{ }^{0} \mathrm{C}$. Volume air yang digunakan adalah $50 \mathrm{ml}$ dan pencucian dilakukan dengan menggunakan beaker glass. Zeolit yang akan dicuci direndam dalam larutan air dan diaduk dengan magnetic stirrer selama 15 menit. Sisa air yang tersisa dalam zeolit kemudian diuapkan dengan cara memanaskan zeolit dalam oven 105 ${ }^{0} \mathrm{C}$ selama 2 jam.

\section{Hasil dan Pembahasan}

\section{Aktivasi Katalis H-Zeolit dengan Asam Klorida dan Asam Sulfat}

Pada penelitian ini dilakukan proses dealuminasi dan aktivasi zeolit dengan 1 dan menggunakan $\mathrm{HCl}$ dan $\mathrm{H}_{2} \mathrm{SO}_{4} 4 \mathrm{M}$, yang bertujuan untuk mengganti aluminium dengan hidrogen yang disertai dengan perubahan struktur aluminosilikiat Si-O-Al menjadi sianol yaitu -Si-OH, proses ini secara langsung juga akan meningkatkan rasio $\mathrm{Si} / \mathrm{Al}$ zeolit. Penelitian Pardoyo,dkk (2009) menyatakan bahwa pemakaian konsentrasi $\mathrm{HCl}$ yang semakin tinggi, akan meningkatkan proses dekristalisasi, namun pada konsentrasi 4M diperoleh \% kristalinitas yang masih tinggi yaitu 101,10 \% [17], perubahan kristalinitas akan mempengaruhi stabilitas fungsional [18].

Dari Tabel 1 dapat dilihat terjadi penurunan kadar aluminium dari 3,67\% menjadi $1,31 \%$ untuk asam klorida, dan $1,72 \%$ untuk asam sulfat hal ini menunjukkan terjadinya proses dealuminasi oleh ion $\mathrm{H}^{+}$dari $\mathrm{HCl}$, dan terjadi peningkatan kadar $\mathrm{SiO}_{2}$ hal ini sesuai dengan penelitian Pardoyo,dkk (2013) dimana kenaikan kadar $\mathrm{SiO}_{2}$ sebanding dengan penurunan kadar Al. Kenaikan rasio Si/Al yang lebih besar terjadi pada zeolit yang diaktivasi dengan asam klorida dibanding oleh asam sulfat hal ini diakibatkan karena nilai konstanta disosiasi asam $\mathrm{HCl}$ yang jauh lebih besar dibanding dengan asam sulfat, yang mengakibatkan $\mathrm{HCl}$ cenderung lebih cepat melepaskan proton nya kedalam larutan, sehingga meningkatkan proses dealuminasi.

Tabel 1. Hasil Analisis Komposisi Aluminium dan Silika Zeolit Sebelum dan Setelah Aktivasi oleh $\mathrm{HCl}$ dan $\mathrm{H}_{2} \mathrm{SO}_{4}$

\begin{tabular}{|l|l|l|l|}
\hline \multirow{2}{*}{ Parameter } & \multicolumn{3}{|c|}{ Hasil Uji } \\
\cline { 2 - 4 } & $\begin{array}{l}\text { Sebelum } \\
\text { Aktivasi }\end{array}$ & $\begin{array}{l}\text { Aktivasi } \\
\text { oleh } \mathrm{HCl}\end{array}$ & $\begin{array}{l}\text { Aktivasi } \\
\text { oleh } \mathrm{H}_{2} \mathrm{SO}_{4}\end{array}$ \\
\hline $\mathrm{Al}(\%)$ & 3,67 & 1,31 & 1,72 \\
\hline $\mathrm{SiO}_{2}(\%)$ & 83,41 & 92,31 & 83,49 \\
\hline Rasio Si/Al & 22,73 & 70,47 & 22,72 \\
\hline
\end{tabular}

Naiknya rasio $\mathrm{Si} / \mathrm{Al}$ menunjukkan terjadinya dealuminasi pada situs aktif $\mathrm{Al}-\mathrm{OH}$ dan Si-O-Al dengan lepasnya $\mathrm{Al}$ dari situs aktif $\mathrm{Si}-\mathrm{O}-\mathrm{Al}$ akan menyebabkan penataan kembali Si-O-Si dari luar kerangka sehingga menyebabkan jumlah komposisi $\mathrm{Si}$ dalam kerangka akan bertambah [10]

\section{Karakteristik FTIR (Fourier Transform Infra Red) Gliserol Tribenzoat}

Karakterisasi FTIR (Fourier Transform Infra Red) gliserol tribenzoat dilakukan untuk mengidentifikasi gugus fungsi dari gliserol tribenzoat yang diperoleh melalui proses esterifikasi. Karakteristik FTIR dari gliserol tribenzoat dapat dilihat pada Gambar 1

Gliserol tribenzoat memiliki gugus ester, pada umumnya memilki panjang gelombang 1700 - $1750 \mathrm{~cm}^{-1}$ [1]. Pada Gambar 4.1 diatas terdapat panjang gelombang $1689,64 \mathrm{~cm}^{-1}$ yang mendekati spektra ester. Beberapa gugus karbonil ester dapat muncul pada area spektra yang sama dengan keton yaitu sekitar 1680 $1700 \mathrm{~cm}^{-1}$, dalam hal ini yang membedakannya dengan keton adalah pada ester bentangan getaran C-O pada daerah (1300-1000 $\left.\mathrm{cm}^{-1}\right)$ kuat, luas dan jelas, sedangkan pada keton lemah, sempit dan kurang jelas [6]. Pada Gambar 1 terdapat 6 puncak yang luas dan jelas pada daerah bentangan getaran C-O (1300-1000 $\left.\mathrm{cm}^{-1}\right)$. 




\section{Gambar 1. Karakteristik FTIR (Fourier Transform Infra Red) Sampel Produk Gliserol Tribenzoat}

Pada daerah sidik jari ini diperoleh kecocokan anatara spektra sampel dengan spectra standar gliserol tribenzoat, sehingga dapat diambil kesimpulan bahwa produk yang dihasilkan adalah gliserol tribenzoat.

\section{Pengaruh Persen Berat Katalis H-Zeolit yang diaktivasi Terhadap Rendemen Gliserol Tribenzoat}

Pada gambar 2 dapat dilihat bahwa terjadi kenaikan nilai rendemen yang signifikan antara penambahan katalis 5\% dan 6\%, namun setelah itu terjadi penurunan nilai rendemen saat persen katalis $7 \%$ dan $8 \%$, sehingga diperoleh rendemen gliserol tribenzoat tertinggi pada saat $\%$ berat katalis H-Zeolit 6\%, yaitu 68.992\%.

Penurunan rendemen pada persen katalis $7 \%$ dan $8 \%$ dimungkinkan terjadi akibat tahanan difusi, karena kondisi reaksi yang menjadi sangat viskos [15]. Difusi molekul menuju sisi aktif katalis dapat menjadi pembatas proses pada penggunaan katalis padat asam berpori seperti zeolit [22] hal ini menyebabkan penambahan katalis lebih lanjut tidak akan meningkatkan nilai rendemen. Hal lain yang mungkin menyebabkan penurunan rendemen adalah penurunan selektivitas zeolit terhadap gliserol tribenzoat seiring dengan penambahan katalis [26].

Faktor lain yang menyebabkan penurunan nilai rendemen adalah pada penambahan katalis sebanyak $7 \%$ dan $8 \%$ mengakibatkan semakin banyak anion yang terbentuk oleh katalis karena situs asam bronsted pada zeolit telah melepaskan proton untuk proses katalitik [7], hal ini menyebabkan tugas metanol sebagai pelarut protik menjadi lebih berat sedangkan jumlah metanol yang digunakan untuk meyeimbangkan anion konstan untuk setiap perlakuan, hal ini memungkinkan sistem yang kelebihan anion menjadi tidak seimbang untuk terjadinya proses katalisis yang baik

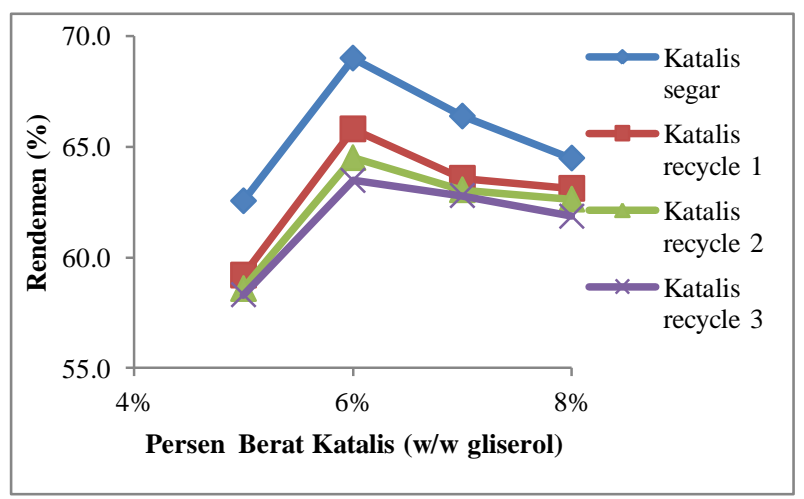

Gambar 2. Grafik Hubungan \% Berat Katalis $\mathrm{H}-Z$ Zeolit Teraktivasi oleh $\mathrm{HCl}$ dengan Rendemen Gliserol Tribenzoat

Hasil yang diperoleh untuk zeolit yang diaktivasi dengan $\mathrm{H}_{2} \mathrm{SO}_{4}$ cukup berbeda, pada Gambar 3 dilihat bahwa semakin besar persen berat katalis $\mathrm{H}$ - Zeolit yang digunakan maka 
rendemen gliserol tribenzoat yang diperoleh semakin meningkat. Rendemen pada persen berat katalis 7 dan $8 \%$ tidak ada perbedaan yang signifikan sehingga diharapkan reaksi sudah mencapai kesetimbangan. penggunaan katalis dengan kondisi segar untuk persen berat katalis $8 \%$ menghasilkan rendemen gliserol tribenzoat yang lebih tinggi yaitu $69,677 \%$. Hal ini menunjukkan bahwa dengan penambahan jumlah katalis dapat mempercepat tercapainya kesetimbangan. Rendemen ester mengalami penurunan pada jumlah katalis $7 \%$ kemudian mengalami kenaikan lagi pada jumlah katalis $8 \%$. Hal ini menunjukkan bahwa kenaikan jumlah katalis yang berlebih dari yang seharusnya memiliki efek merusak pada rendemen ester.

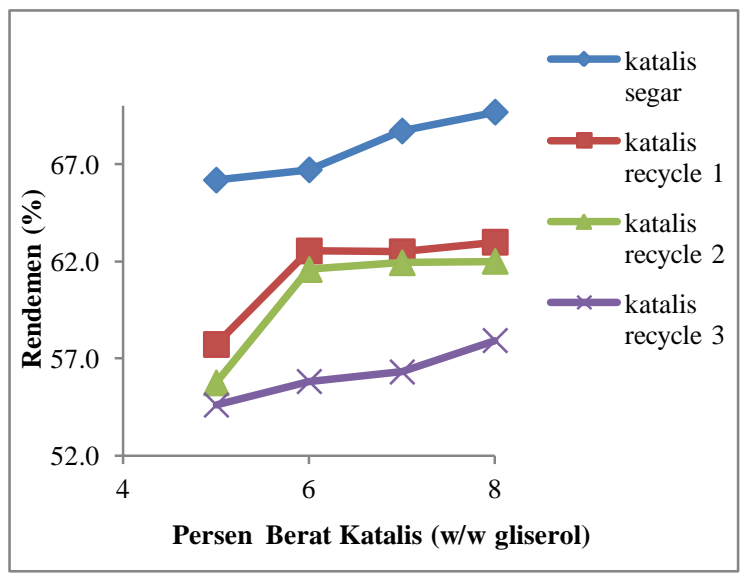

\section{Gambar 3. Grafik Hubungan \% Berat Katalis H-Zeolit Teraktivasi oleh $\mathrm{H}_{2} \mathrm{SO}_{4}$ dengan Rendemen Gliserol Tribenzoat}

Pada pemakaian katalis recycle 1 , Seperti halnya pada penelitian Vijayakumar, et al., dimana reaksi o-xylene menggunakan rasio molar reaktan 1:2 menghasilkan yield yang lebih tinggi dengan meningkatnya jumlah katalis sampai kuantitas katalis tercapai $1 \mathrm{~g}$, tetapi selanjutnya yield menurun [24]. Hal ini menunjukkan bahwa pada katalis zeolit yang diaktivasi oleh $\mathrm{H}_{2} \mathrm{SO}_{4}$ belum mengalami hambatan difusi pori pada persen berat $>6 \%$. Nilai Si/Al yang lebih kecil yang berarti juga nilai keasaman yang lebih rendah juga mengindikasikan lebih sedikit anion yang terbentuk oleh katalis sebagai akibat dari pelepasan asam bronsted, sehingga metanol sebagai pelarut protik masih mampu untuk menyeimbangkan anion yang terbentuk.

\section{Pengaruh Recycle Katalis H-Zeolit Terhadap Rendemen Gliserol Tribenzoat}

Pada gambar 4 menunjukkan performa katalis yang diaktivasi dengan $\mathrm{HCl}$ menurun pada saat dilakukan recycle. Penurunan performa ditandai dengan penurunan nilai rendemen gliserol tribenzoat. Penurunan yang signifikan terjadi antara pemakaian pertama (katalis segar) terhadap katalis recycle 1, sedangkan pada recycle yang ke 2 dan ke 3 penurunannya tidak terlalu signifikan.

Pada Gambar 5 juga terjadi penurunan persen rendemen pada tiap proses recycle namun dari grafik terlihat penurunan rendemen yang signifikan terjadi secara terus menerus, bila dibandingkan dengan $\mathrm{HCl}$ yang penurunannya tidak terlalu besar setelah proses recycle pertama. Hal ini disebabkan oleh rasio Si/Al yang lebih besar pada zeolit yang teraktivasi $\mathrm{HCl}$.

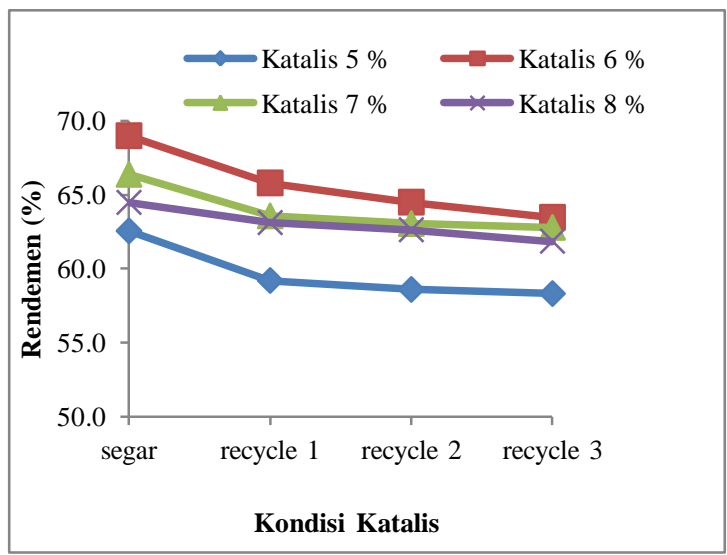

Gambar 4. Grafik Hubungan Recycle HZeolit Teraktivasi $\mathrm{HCl}$ dengan Rendemen Gliserol Tribenzoat

Penurunan nilai rendemen ini juga mengindikasikan penurunan aktivitas katalitik karena pengurangan nilai mesoporitas dan luas area yang pada umumnya disebabkan oleh pembentukan air selama reaksi, karena air akan mengakibatkan peracunan pada sisi asam (acid side) dari katalis padat namun katalis H-zeolit merupakan salah satu jenis katalis padat yang toleran terhadap pembentukan air, hal ini disebabkan oleh proses dealuminasi yang meningkatkan nilai rasio $\mathrm{Si} / \mathrm{Al}$ yang juga 
meningkatkan hidrofobitas katalis [23]. Sehingga dalam kasus ini penyebab utama berkurangnya mesoporitas, dan sisi aktif dapat disebabkan oleh adanya penumpukan pengotor (impurities) berupa produk samping ataupun reaktan yang tidak bereaksi pada permukaan katalis, ataupun pada bagian mesopore zeolit.

Struktur mesopore juga dapat hancur akibat proses recovery katalis dimana katalis dicuci dengan air, dan proses pengeringan dengan oven, sehingga kedepannya modifikasi proses recovery yang lebih tepat dapat mengurangi laju deaktivasi katalis H-zeolit, seperti pengeringan yang disertai dengan purging katalis dengan gas nitrogen. Penurunan mesoporitas menyebabkan berkurangnya kontak antara reaktan dan acid side, dan meningkatkan hambatan difusi menuju zeolit [21].

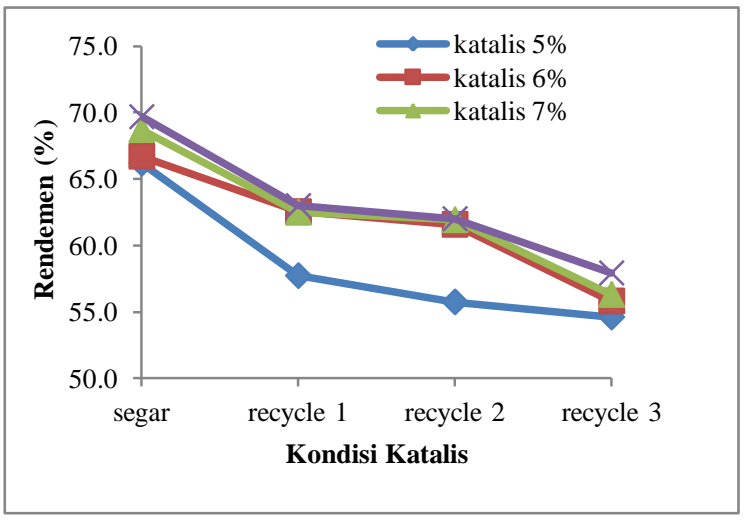

Gambar 5. Grafik Hubungan Recycle HZeolit Teraktivasi $\mathrm{H}_{2} \mathrm{SO}_{4}$ dengan Rendemen Gliserol Tribenzoat

Dari data yang diperoleh maka penggunaan kembali katalis layak dilakukan, karena penurunan nilai rendemen pada tiap recycle $\leq$ $8 \%$.

\section{Kesimpulan}

Kesimpulan yang dapat diambil dari penelitian ini adalah :

1. Katalis zeolit alam yang diaktivasi menggunakan $\mathrm{HCl}$ memiliki rasio $\mathrm{Si} / \mathrm{Al}$ 70,47 sedangkan oleh $\mathrm{H}_{2} \mathrm{SO}_{4}$ 48,5 dengan aktivitas katalitik cukup tinggi, dimana masing-masing menghasilkan rendemen gliserol tribenzoat sebesar $68,992 \%$ dan $69,678 \%$.

2. Pada pembuatan gliserol tribenzoat dengan proses esterifikasi diperoleh $\%$ berat katalis $\mathrm{H}$-zeolit optimum untuk $\mathrm{HCl}$ dan $\mathrm{H}_{2} \mathrm{SO}_{4}$ masing- masing sebesar $6 \%$ dan $8 \%$ $(\mathrm{w} / \mathrm{w})$.

3. Recycle katalis H-zeolit yang diaktivasi oleh $\mathrm{HCl}$ dan $\mathrm{H}_{2} \mathrm{SO}_{4}$ mengalami penurunan aktivitas katalitik dengan kondisi layak pakai hingga 3 kali recycle dengan persen penurunan rendemen tiap kali recycle $\leq 8 \%$.

\section{Daftar Pustaka}

[1] Arthur Israel Vogel, Textbook of Practical Organic Chemistry, Edisi Kelima, Penerbit Prentice Hall, 1996.

[2] Ari Eko Prasetyo, Anggra Widhi, dan Widayat, Proses Reaksi Gliserol dan Asam Benzoat Dengan Menggunakan Katalis Asam Sulfat, Jurnal Teknologi Kimia dan Industri. Vol.1.No.1, p. 118 - 123, 2003.

[3] Arief Budiawan Majid, dkk,. "Karakterisasi dan Uji Aktivitas katalitik Zeolit Alam Indonesia pada Hidrorengkah Ban Bekas dengan Preparasi Sederhana. Prosiding Seminar Nasional Kimia Unesa. ISBN : 978-979-028-550-7.Hal.216,2012.

[4] Arno Behr, Jens Eilting, Ken Irawadi, Julia Leschinski, dan Falk Linder, Improved Utilisation of Renewable Resources : New Important Derivatives of Glycerol, Green Chemistry,Vol.10. No.1, p.1 -140, 2003.

[5] Avelino Corma, State Of The Art And Future Challenges Of Zeolites As Catalysts, Journal of Catalyst 216, p.298-312, 2003.

[6] Cayo Emilio Goncalves, Leticia Olivera Laier, dan Marco Jose Da Silva, Novel Esterification of Glycerol Catalysed by Tin Cholride (II) : A Recyclabe and Less Corossive Process for Production of BioAdditives, Springer Science Business Media, p.1111-1117, 2011.

[7] Eddy Heraldy, Hisyam SW, Sulistiyono. Characterization And Activation Of Natural Zeolit From Ponorogo. Indonesian Journal Of Chemistry,3(2),p. 96, 2003.

[8] Fadhel, et al., Combining The Benefits of Homogeneous and Heterogeneous Catalysis with Tunable Solvents and Nearcritical Water. Molecules, ISSN : 1420 - 3049, p.8401, 2010 .

[9] Heri Hermansyah, Tania Surya Utami, Rita Arbianti, dan Fajar Achmadi, Simulasi Reaksi Esterifikasi Asam Lemak Bebas dan Gliserol Untuk Menghasilkan Minyak Diasilgliserol, Reaktor, Vol.13, No.2, p 95 $-102,2010$. 
[10] Is Fatimah, Penggunaan Na- Zeolit Alam Teraktivasi Sebagai Penukar Ion $\mathrm{Cr}^{3+}$ dalam Larutan, LOGIKA, VI, hal. 28, 2000.

[11] Ismail Kirbaslar, Z. Brais Baykal, dan Umur Dramur, Esterification of Acetic Acid with Ethanol Catalysed by an Acidic Ion-Exchange Resin, Turky Journal Engineering Enviromental Science 25, p.569-577, 2001.

[12] J.J Tamayo, M. Ladero, V.E. Santos, dan F. Garcia-Ochoa, "Esterification of Benzoic Acid Glycerol To $\alpha$ - Monobenzoate Glycerol in Solventless Media Using an Industrial Free Candida Antartica Lipase B", Process Biochemistry 47, p. 243 - 250, 2012.

[13] Jihad Mohammed Dakka, Edmund J. Mozeleski, Lisa Saunders Baugh, Process for making Triglyceride Plasticizer from Crude Glycerol, US Patent Application Publication, 2012.

[14] L Shirazi, E. Jamshidi, dan M.R. Ghasemi, The Effect of Si/Al Ratio of ZSM-5 Zeolite On its Morphology, Acidity, and Crystal Size, Crystal Res. Technology, Vol.43. No.12, p. 1300 -1306, 2008.

[15] M.da S Machado, J.Perez-pariente, E.Sastre, D.Cardoso, A.M. de Guerenu, Selective Synthesis Of Glycerol Monolaurate With Zeolitic Molecular Sieves, Applied Catalyst A : General 203 , p. 321- 328, 2000.

[16] M.T Nowaks dan Mass Gadner, Benzoate Ink, US Patent Application Publication, 1990.

[17] Pardoyo, Listiana dan Adi Darmawan, Pengaruh Perlakuan HCl Pada Kristalinitas dan Kemampuan Adsorpsi Zeolit Alam Terhadap Ion $\mathrm{Ca}^{2+}$, Jurnal Sains \& Matematika, Vol.17, No.2. p. 100-104, 2009.

[18] Pardoyo, Narsito, dan Nuryono, Studi Pengaruh Dealuminasi Pada Adsorpsi Zeolit Alam Terhadap Ion Logam Cd(Ii) Dalam Medium Air, Jurusan Kimia FMIPA. Universitas Diponegoro, Semarang, 2013.

[19] Paul Z Bedoukian, Citrus Oil and Others Oil Having Enhanced Spessific Gravity and Use Therof, Us Patent Application Publication, 1972.

[20] Randi Farlindo, Nirwana, Irdoni. Pengaruh Komposisi Katalis H- Zeolit dan Suhu Reaksi pada Proses Pembuatan Fatty Acid Alkyl Ester Minyak Limbah Ikan Patin dan
Isooktanol. Program Studi Teknik Kimia. Fakultas Teknik. Universitas Riau,2014.

[21] Sander van Donk., Andries H.Janssen, Johannes H.Bitter, dan Krijn P.de Jong, Generation, Characterization, And Impact Of Mesopores In Zeolite Catalysts, Catalyst Reviews Vol 45. No.2, p. 297 - 319, 2003.

[22] Thijs.A Peters, Nieck E.Benes, Anders Holmen, dan Jos T.F Kurentjes, Comparison of commercial solid acid catalysts for the esterification of acetic acid with butanol, Applied Catalyst A: general 297 , p.182-188, 2006.

[23] Toshio Okuhara, Water- Tolerant Solid Acid Catalyst, American Chemical Society (102), p. 3641 - 3666, 2002.

[24] Vijayakumar, et al. Synthesis of p - tolyl stearate catalyzed by acid activated Indian Bentonite. Indian Journal of Chemical Technology XII ,p. 316 - 321,2005.

[25] Widayat, Achmad Roesyadi,dan Muhammad Rachimoellah, Kinetika Reaksi Proses Produksi Dietil Eter Dari Etanol Dengan Katalis H-Zeolit, Reaktor, Vol,14, No.2, p. 101-108, 2012.

[26] Xiaoyuan Liao, Yulei zhu, Sheng-Guang Wang, dan Yongwang Li, Producing Triacetylglycerol With Glycerol By Two Steps: Esterification And Acetylation, Fuel Processing Technology 90, p.988-993, 2009.

[27] Yanuar Rifianto Abdurrakhman, dan Widayat, Studi Awal Proses Pembuatan Glycerol Tribenzoat Dari Gliserol Dan Asam Benzoat Dengan Menggunakan Katalis Asam Klorida, Jurnal Teknologi Kimia dan Industri, Vol.2, No.3, 2013. 